\title{
Spectroscopy of $\mathrm{K}^{+} \cdot \mathbf{R g}$ and transport coefficients of $\mathrm{K}^{+}$ in $\mathbf{R g}(\mathbf{R g}=\mathrm{He}-\mathrm{Rn})$
}

\author{
Larry A. Viehland ${ }^{\text {a) }}$ \\ Division of Science, Chatham College, Pittsburgh, Pennsylvania 15232 \\ Jérôme Lozeille ${ }^{\text {b) }}$ \\ Department of Chemistry, University of Sussex, Falmer, Brighton, United Kingdom BN1 9QJ
}

Pavel Soldán

Department of Chemistry, University of Durham, South Road, Durham, United Kingdom DH1 3LE

Edmond P. F. Lee ${ }^{\text {c) }}$

School of Chemistry, University of Southampton, Highfield, Southampton, United Kingdom SO17 1BJ

and Department of Applied Biology and Chemical Technology, Hong Kong Polytechnic University,

Hung Hom, Hong Kong

Timothy G. Wright ${ }^{d)}$

Department of Chemistry, University of Sussex, Falmer, Brighton, United Kingdom BN1 9QJ

(Received 6 February 2004; accepted 10 March 2004)

\begin{abstract}
$A b$ initio calculations employing the coupled-cluster method, with single and double substitutions and accounting for triple excitations noniteratively $[\operatorname{CCSD}(\mathrm{T})]$, are used to obtain accurate potential energy curves for the $\mathrm{K}^{+} \cdot \mathrm{He}, \mathrm{K}^{+} \cdot \mathrm{Ne}, \mathrm{K}^{+} \cdot \mathrm{Ar}, \mathrm{K}^{+} \cdot \mathrm{Kr}, \mathrm{K}^{+} \cdot \mathrm{Xe}$, and $\mathrm{K}^{+} \cdot \mathrm{Rn}$ cationic complexes. From these potentials, rovibrational energy levels and spectroscopic parameters are calculated. In addition, mobilities and diffusion coefficients for $\mathrm{K}^{+}$cations moving through the six rare gases are calculated, under conditions that match previous experimental determinations. A detailed statistical comparison of the present and previous potentials is made with available experimental data, and critical conclusions are drawn as to the reliability of each set of data. It is concluded that the present $a b$ initio potentials match the accuracy of the best model potentials and the most reliable experimental data. () 2004 American Institute of Physics. [DOI: 10.1063/1.1735560]
\end{abstract}

\section{INTRODUCTION}

The interactions of closed-shell alkali-metal cations with closed-shell neutral rare gas atoms have received a very large amount of attention over the years. These are prototypical systems because of the absence of complications that arise in open-shell systems. Of course, the accuracy of $a b$ initio methods has improved tremendously in the years since the first comparisons between derived potentials obtained from ion beam studies ${ }^{1,2}$ and initial ion mobility studies. ${ }^{3,4}$ It was the lighter $\mathrm{K}^{+} \cdot \mathrm{Rg}(\mathrm{Rg}=$ rare gas) systems that were employed in the first such comparisons, ${ }^{1,3}$ we tackle these systems again, but extend the study to the complete set of six $\mathrm{K}^{+} \cdot \mathrm{Rg}$ systems $(\mathrm{Rg}=\mathrm{He}-\mathrm{Rn})$. The work follows from our previous studies of the six $\mathrm{Li}^{+} \cdot \mathrm{Rg}$ (Ref. 5) and six $\mathrm{Na}^{+}$ - Rg (Ref. 6) systems, where we showed that our potentials were either comparable to or of a better quality than those previously available. We were also able to analyze critically previous experimental results and draw conclusions as to the reliability of those data. We are in the process of completing a study of the heavier species: $\mathrm{Rb}^{+} \cdot \mathrm{Rg}, \mathrm{Cs}^{+} \cdot \mathrm{Rg}$, and $\mathrm{Fr}^{+}$ $\cdot \mathrm{Rg}$, and those results will be published in due course.

\footnotetext{
a)Electronic mail: Viehland@chatham.edu

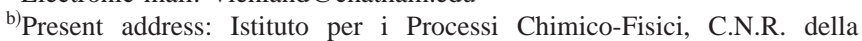
Ricerca di Pisa, Via G. Moruzzi 1, 56124 Pisa, Italy.

${ }^{c}$ Electronic mail: E.P.Lee@soton.ac.uk

${ }^{d)}$ Fax: +44 1273 677196. Electronic mail: T.G.Wright@ sussex.ac.uk
}

In the present paper, we report high-quality $\operatorname{CCSD}(\mathrm{T})$ potential energy curves, using basis sets of quadruple- and quintuple- $\zeta$ quality. All-electron basis sets are employed for the lighter $\mathrm{Rg}$ atoms, $\mathrm{He}-\mathrm{Ar}$, while (relativistic) effectivecore potentials (ECPs) are employed for the heavier species, $\mathrm{Kr}-\mathrm{Rn}$. For $\mathrm{K}^{+}$, both all-electron and potentials based upon ECPs are employed - these are described below.

We note that Bellert and Breckenridge ${ }^{7}$ have recently provided a thorough survey of the information available on the interactions that occur between metal atomic cations and rare gas atoms.

\section{THEORETICAL DETAILS}

\section{A. Ab initio calculations}

$\operatorname{CCSD}(\mathrm{T})$ calculations were employed to calculate interatomic potentials over a wide range of separations, as demanded by the transport property calculations (vide infra). The basis sets employed for the $\mathrm{Rg}$ atoms were essentially those used in our previous study on the $\mathrm{Na}^{+} \cdot \mathrm{Rg}$ species. ${ }^{6}$

For $\mathrm{He}-\mathrm{Ar}$, the standard aug-cc-pVQZ (denoted aVQZ hereafter) and aug-cc-pV5Z (denoted aV5Z hereafter) basis sets were employed. For He, we also employed the doubleaugmented version of the quintuple- $\zeta$ basis set (d-aug-ccpV5Z, denoted d-aV5Z hereafter), since double augmentation can help to describe the hyperpolarizability more accurately. ${ }^{8}$ 
For $\mathrm{Kr}, \mathrm{Xe}$, and $\mathrm{Rn}$, the basis sets may be represented by ECP28MWB[ $8 s 7 p 5 d 3 f 2 g]$, ECP46MWB[ $6 s 6 p 4 d 3 f 2 g$ ], ECP78MWB[ $10 s 9 p 7 d 4 f 2 g]$, respectively. In each case, the number of core electrons is represented by the number, the $\mathrm{M}$ generally indicates that the neutral atom is used in the derivation of the ECP, WB implies the use of the quasirelativistic approach described by Wood and Boring, ${ }^{9}$ and the contracted valence basis set is indicated in brackets. The $\mathrm{Kr}$ and Xe basis sets are detailed in Ref. 5, the Rn basis set is detailed in Refs. 10 and 11.

For potassium, two basis sets were employed. The first was the [10s9p6d4f2g] all-electron basis set used in Ref. 12 (where it was called AE-B). It is a $(23 s 19 p 6 d 4 f 2 g) /$ $[10 s 9 p 6 d 4 f 2 g]$ contraction of the Feller Misc. CVQZ basis set from Gaussian Basis Order Form. ${ }^{13}$ For simplicity of presentation, "aVQZ" will be used to describe the use of this $\mathrm{K}^{+}$basis set with the corresponding $\mathrm{Rg}$ basis set, i.e., the standard aug-cc-pVQZ basis sets for $\mathrm{He}-\mathrm{Ar}$ and the ECP basis sets for $\mathrm{Kr}-\mathrm{Rn}$.

The second basis set employed for potassium was the ECP-2 basis set described in full in Ref. 14. It comprises the ECP10MWB (Ref. 15) ECP, which describes the $1 s-2 p$ electrons augmented with a large, flexible valence basis set (note that for $\mathrm{K}^{+}$the valence electrons are the $3 s$ and $3 p$ ), which may be summarized as $(29 s 23 p 5 d 4 f 3 g) /$ $[10 s 9 p 5 d 4 f 3 g]$. This basis set was used in conjunction with standard aug-cc-pV5Z basis sets for $\mathrm{He}-\mathrm{Ar}$, but omitting the $h$ functions, and additionally with the d-aug-ccpV5Z basis set for He. For simplicity of presentation, "aV5Z" will be used to describe the use of this $\mathrm{K}^{+}$basis set with the aug-cc-pV5Z (no h) basis set for the corresponding $\mathrm{Rg}$ atom; with d-aV5Z being used when the d-aug-cc-pV5Z basis set was employed for He.

Energies were determined at a range of intermolecular separations, $R$, covering the short- as well as long-range regions. The ranges of $R$ used were selected based upon the position of the minimum and upon the demands of the transport property calculations. Basis set superposition error (BSSE) was accounted for by employing the full counterpoise correction of Boys and Bernardi ${ }^{16}$ in a point-by-point manner. All energy calculations were performed employing MOLPRO. ${ }^{17}$ The frozen core approximation was used when the all-electron basis set was employed for $\mathrm{K}^{+}$, with the potassium $1 s, 2 s$, and $2 p$ orbitals frozen. The frozen core approximation obviously affects the calculated total energy, but we showed in Ref. 18 that the freezing of the core orbitals had a negligible effect on the calculated dissociation energy and equilibrium bond length for this type of species.

\section{B. Spectroscopy and interaction parameters}

From the interaction potential energy functions, the equilibrium interatomic separations and the dissociation energies were obtained. Le Roy's LEVEL program ${ }^{19}$ was used to calculate rovibrational energy levels, and the $\omega_{e}$ and $\omega_{e} x_{e}$ parameters were then determined from the calculated energy levels by straightforward means.

The rotational energy levels for each vibrational level were fitted to the expression,

$$
\begin{aligned}
E(v, J)= & E(v, 0)+B_{v} J(J+1)-D_{v} J^{2}(J+1)^{2} \\
& +H_{v} J^{3}(J+1)^{3}
\end{aligned}
$$

although the $H_{v}$ term was not always statistically meaningful, and so only $B_{v}$ and $D_{v}$ are reported herein.

\section{Transport coefficients}

Starting from the interaction potentials, transport cross sections were calculated using the program QVALUES, ${ }^{20,21}$ and these cross sections were then used in the program GRAMCHAR (Ref. 22) to determine the ion mobility and the other gaseous ion transport coefficients as functions of $E / N$ (the ratio of the electric field strength to the gas number density) at particular gas temperatures. The mobilities are generally precise within $0.1 \%$, which means that the numerical procedures within programs QVALUES and GRAMCHAR have converged within $0.1 \%$ for the given ion-neutral interaction potential. However, at some intermediate $E / N$ values convergence is sometimes only within a few tenths of a percent and a slight "wobble" is observed in the computed values for the heavier rare gases. The diffusion coefficients are generally precise within $1 \%$, with the exception of intermediate $E / N$ values where convergence is only within $3 \%$.

\section{RESULTS}

\section{A. Potential energy curves and spectroscopic constants}

Our ion-neutral interaction potential energies are given in Table I. For a closed-shell atom interacting with a singlecharged ion at long range,

$$
U(R)=-\frac{D_{4}}{R^{4}}-\frac{D_{6}}{R^{6}}+\cdots .
$$

Ignoring the higher order terms, Ahlrichs et al. ${ }^{23}$ (among others) have noted that $D_{4}$ and $D_{6}$ are related to the other parameters by

$$
\begin{aligned}
& D_{4}=\alpha_{1} / 2, \\
& D_{6}=\alpha_{2} / 2+C_{6}\left(\mathrm{~K}^{+} \cdot \mathrm{Rg}\right),
\end{aligned}
$$

where $\alpha_{1}$ is the static dipolar polarizability (or simply static polarizability), $\alpha_{2}$ is the static quadrupolar polarizability of the rare gas atom, and $C_{6}$ is a dispersion coefficient. As a consequence of Eq. (2), least-squares fitting of the calculated potentials at large $R$ allows values for the parameters $D_{4}$ and $D_{6}$ to be derived, with the possibility of incorporating "universal damping functions" in the fit (see e.g., Ref. 23). However, it has been noted by Ahmadi et al. ${ }^{24}$ that this can lead to significant error in the fitted potential, so, as in Ref. 6, we refrain from such fits in the present work. We confirmed that the potentials at very large $R$ have the expected $-D_{4} / R^{4}$ dependence, and that the value of $D_{4}$ was consistent with well-established values for the polarizabilities of $\mathrm{He}-\mathrm{Ar}$, and with the values for $\mathrm{Kr}-\mathrm{Rn}$ calculated by ourselves ${ }^{8}$ and others. 
TABLE I. CCSD(T) potentials for $\mathrm{K}^{+} \cdot \mathrm{He}, \mathrm{K}^{+} \cdot \mathrm{Ne}$, and $\mathrm{K}^{+}$. Ar. Energies are given with respect to the relevant dissociation limit.

\begin{tabular}{|c|c|c|c|c|c|c|}
\hline \multirow[b]{2}{*}{$R / \AA$} & \multicolumn{6}{|c|}{$V(R) / \mathrm{cm}^{-1}$} \\
\hline & $\mathrm{K}^{+} \cdot \mathrm{He}^{\mathrm{a}}$ & $\mathrm{K}^{+} \cdot \mathrm{Ne}^{\mathrm{b}}$ & $\mathrm{K}^{+} \cdot \mathrm{Ar}^{\mathrm{b}}$ & $\mathrm{K}^{+} \cdot \mathrm{Kr}^{\mathrm{c}}$ & $\mathrm{K}^{+} \cdot \mathrm{Xe}^{\mathrm{c}}$ & $\mathrm{K}^{+} \cdot \mathrm{Rn}^{\mathrm{c}}$ \\
\hline 1.00 & 164179.19 & 408766.10 & 806413.70 & & & \\
\hline 1.20 & 80980.10 & 208778.45 & 425451.70 & & & \\
\hline 1.40 & 37753.21 & 98952.46 & 291531.50 & & & \\
\hline 1.60 & 16676.88 & 43752.87 & 123648.41 & & & \\
\hline 1.70 & 10835.66 & 28492.85 & 88148.06 & & & \\
\hline 1.90 & 4303.54 & 11531.62 & 43133.86 & & & \\
\hline 2.00 & 2595.14 & 7109.77 & 29541.68 & 44953.80 & 72862.34 & 86777.97 \\
\hline 2.10 & 1491.95 & 4246.55 & 19884.70 & & & \\
\hline 2.20 & 792.12 & 2416.10 & 13092.35 & & & \\
\hline 2.30 & 358.03 & 1264.27 & 8364.44 & 14543.06 & 26861.75 & 33188.78 \\
\hline 2.40 & 96.77 & 554.36 & 5111.13 & & & \\
\hline 2.50 & -53.76 & 129.27 & 2902.42 & & & \\
\hline 2.60 & -134.60 & -114.47 & 1427.67 & 3520.05 & 8334.05 & 11091.21 \\
\hline 2.70 & -172.56 & -244.63 & 464.19 & & & \\
\hline 2.80 & -184.92 & -305.05 & -146.49 & 675.72 & 2969.68 & 4422.32 \\
\hline 2.90 & -182.63 & -323.84 & -516.41 & -78.95 & 1404.24 & 2408.08 \\
\hline 3.00 & -172.53 & -318.83 & -724.27 & -557.76 & 326.08 & 982.71 \\
\hline 3.10 & -158.77 & -301.07 & -824.90 & -844.47 & -397.41 & -6.33 \\
\hline 3.20 & -143.80 & -277.36 & -856.30 & -999.25 & -864.77 & -673.98 \\
\hline 3.30 & -129.00 & -251.68 & -844.46 & -1065.08 & -1149.01 & -1106.62 \\
\hline 3.40 & -115.09 & -226.29 & -806.96 & -1072.48 & -1304.05 & -1369.12 \\
\hline 3.50 & -102.40 & -202.40 & -755.52 & -1042.86 & -1369.43 & -1509.94 \\
\hline 3.60 & -91.04 & -180.56 & -697.78 & -991.08 & -1374.02 & -1565.15 \\
\hline 3.70 & -80.97 & -160.94 & -638.60 & -927.32 & -1338.69 & -1561.51 \\
\hline 3.80 & -72.12 & -143.50 & -580.95 & -858.37 & -1278.41 & -1518.65 \\
\hline 3.90 & -64.36 & -128.13 & -526.51 & -788.68 & -1203.74 & -1450.88 \\
\hline 4.00 & -57.57 & -114.62 & -476.16 & -721.01 & -1122.06 & -1368.51 \\
\hline 4.10 & & & & -657.00 & -1038.37 & -1278.82 \\
\hline 4.20 & -46.41 & -92.35 & -388.71 & & & \\
\hline 4.25 & & & & -569.60 & -915.99 & -1141.19 \\
\hline 4.40 & & & & -493.23 & -802.71 & -1008.74 \\
\hline 4.50 & -34.27 & -68.04 & -288.28 & & & \\
\hline 4.70 & & & & -371.35 & -612.10 & -777.66 \\
\hline 5.00 & -21.71 & -42.87 & -181.28 & -283.03 & -468.18 & -597.89 \\
\hline 5.50 & -14.46 & -28.35 & -119.64 & -186.26 & -307.21 & -392.97 \\
\hline 6.00 & -10.03 & -19.53 & -82.33 & -127.75 & -209.51 & -267.49 \\
\hline 6.50 & -7.18 & -13.90 & -58.61 & & & \\
\hline 7.00 & -5.28 & -10.19 & -42.92 & -66.38 & -107.94 & -137.16 \\
\hline 7.50 & -3.97 & -7.65 & -32.18 & & & \\
\hline 8.00 & -3.05 & -5.86 & -24.64 & & & \\
\hline 9.00 & -1.89 & -3.61 & -15.18 & & & \\
\hline 10.00 & -1.23 & -2.35 & -9.87 & -15.24 & -24.55 & -31.01 \\
\hline 12.00 & -0.59 & -1.11 & -4.71 & & & \\
\hline 13.00 & & & & -5.28 & -10.67 & -8.46 \\
\hline 15.00 & -0.24 & -0.45 & -1.91 & -2.98 & -5.99 & -4.76 \\
\hline 17.00 & & & & -1.82 & -3.63 & -2.89 \\
\hline 20.00 & -0.08 & -0.13 & -0.60 & -0.97 & -1.90 & -1.52 \\
\hline 22.00 & & & & -0.67 & -1.31 & -1.05 \\
\hline 25.00 & -0.04 & -0.05 & -0.25 & -0.42 & -0.80 & -0.64 \\
\hline
\end{tabular}

ad-aV5Z basis set, see text.

bav5Z basis set, see text.

${ }^{\mathrm{c}}$ See text for basis sets.

\section{1. $\mathrm{K}^{+} \cdot \mathrm{He}$}

Although there has been some earlier theoretical work, we concentrate here on the most recent studies. The first curves we consider are those of Koutselos, Mason, and Viehland $^{25}$ (denoted KMV hereafter), who derived their curve from a "universal scaling" and fitting to available ion mobility data; they obtained $D_{e}=164 \mathrm{~cm}^{-1}$, and $R_{e}$ $=2.91 \AA$. Moszynski et al. ${ }^{26}$ calculated the whole potential using symmetry-adapted perturbation theory (SAPT), and they used the potential to calculate both rovibrational energy levels and transport coefficients. They obtained $D_{e}$ $=171 \mathrm{~cm}^{-1}$ at $R_{e}=2.87 \AA$, with the potential being found to support 36 bound rovibrational energy levels. Røeggen, Skullerud, and Elford ${ }^{27}$ used an extended group function (EGF) approach to generate a potential energy curve, obtaining $D_{e}=177.4 \mathrm{~cm}^{-1}$ and $R_{e}=2.85 \AA$; an error analysis led to 
TABLE II. Calculated spectroscopic parameters for ${ }^{39} \mathrm{~K}^{+} \cdot \mathrm{Rg} \cdot{ }^{\text {a }}$

\begin{tabular}{|c|c|c|c|c|c|}
\hline Species & $R_{e} / \AA$ & $\omega_{e} / \mathrm{cm}^{-1}$ & $\omega_{e} x_{e} / \mathrm{cm}^{-1}$ & $D_{e} / \mathrm{cm}^{-1}$ & Ref. \\
\hline \multirow[t]{7}{*}{$\mathrm{K}^{+} \cdot{ }^{4} \mathrm{He}$} & 2.91 & & & 164 & 25 \\
\hline & 2.87 & $94.4^{\mathrm{b}}$ & $14.6^{\mathrm{b}}$ & 171 & 26 \\
\hline & 2.85 & & & 177.4 & 27 \\
\hline & $2.83^{\mathrm{b}}$ & $101.4^{\mathrm{c}}$ & $15.5^{\mathrm{c}}$ & $185.5^{\mathrm{b}}$ & 28 \\
\hline & 2.818 & 97.2 & 14.9 & 177.8 & This work (aVQZ) \\
\hline & 2.825 & 100.2 & 15.2 & 184.1 & This work (aV5Z) \\
\hline & 2.825 & 100.4 & 15.2 & 185.4 & This work (d-aV5Z) \\
\hline \multirow[t]{4}{*}{$\mathrm{K}^{+} \cdot{ }^{20} \mathrm{Ne}$} & 2.97 & & & 314 & 25 \\
\hline & 2.87 & & & 350 & 29 \\
\hline & 2.940 & 69.0 & 4.50 & 311.9 & This work (aVQZ) \\
\hline & 2.921 & 72.0 & 4.82 & 324.3 & This work (aV5Z) \\
\hline \multirow[t]{5}{*}{$\mathrm{K}^{+} \cdot{ }^{40} \mathrm{Ar}$} & 3.13 & & & 938 & 25 \\
\hline & 3.11 & & & 990 & 29 \\
\hline & 3.42 & & & 490 & 30 \\
\hline & 3.225 & 80.6 & 2.36 & 829.8 & This work (aVQZ) \\
\hline & 3.215 & 82.1 & 2.36 & 856.8 & This work (aV5Z) \\
\hline \multirow[t]{3}{*}{$\mathrm{K}^{+} \cdot{ }^{84} \mathrm{Kr}$} & 3.30 & & & 1135 & 25 \\
\hline & 3.28 & & & 1157 & 29 \\
\hline & 3.356 & 74.1 & 1.51 & 1075.0 & This work \\
\hline \multirow[t]{3}{*}{$\mathrm{K}^{+} \cdot{ }^{132} \mathrm{Xe}$} & 3.35 & & & 1721 & 25 \\
\hline & 3.46 & & & 1510 & 29 \\
\hline & 3.558 & 72.9 & 1.12 & 1378.0 & This work \\
\hline $\mathrm{K}^{+} \cdot{ }^{222} \mathrm{Rn}$ & 3.641 & 71.0 & 0.93 & 1569.5 & This work \\
\hline
\end{tabular}

${ }^{a}$ See text for details.

${ }^{\mathrm{b}}$ Potential of Ref. 26 analyzed in the present work.

${ }^{\text {c} P o t e n t i a l ~ o f ~ R e f . ~} 28$ analyzed in the present work.

the conclusion that the binding energy was not in error by more than $0.4 \%$. In a follow-up paper, ${ }^{28}$ that potential was modified in order to fit mobility measurements better. It was concluded that, over the range of the potential tested by the mobility measurements, unexplained discrepancies of $\sim 1 \%$ still existed between experiment and theory. Finally, Skullerud, Løvaas, and Tsurugida ${ }^{29}$ constructed a model potential with adjustable parameters, based on well-known analytic forms ${ }^{23}$ of the short and long-range regions of $\mathrm{M}^{+} \cdot \mathrm{Rg}$ potentials; by fitting to the previous $a b$ initio values of Ref. 28. The most accurate potential of these has been concluded $^{29}$ to be the modified version of the EGF potential. $^{28}$

We calculated potential energy curves over a wide range of $R$ for the three sets of basis sets: aVQZ, aV5Z, and d-aV5Z. From these curves, we calculated rovibrational energy levels, and used these to extract spectroscopic constants. The values are shown in Table II, and the potential energy curve is shown in Fig. 1. As may be seen from Table II, there is, on the whole, reasonable agreement between the three basis sets, with the difference between aV5Z and d-aV5Z being extremely small. There is a significant difference both in $D_{e}$ and $\omega_{e}$ on going from aVQZ to aV5Z, suggesting that the shape of the curve changes between these two basis sets; the changes between the aV5Z and d-aV5Z levels of theory are very much smaller. Our best values for $D_{e}$ and $R_{e}$ are $185.4 \mathrm{~cm}^{-1}$ and $2.825 \AA$.

In Table III, we present the whole set of bound rovibrational levels obtained from our potential. Note that we obtain 53 bound rovibrational levels, whereas the SAPT potential of Moszynski $^{26}$ only led to 36 : this is likely a consequence of an incomplete description of electron correlation effects in

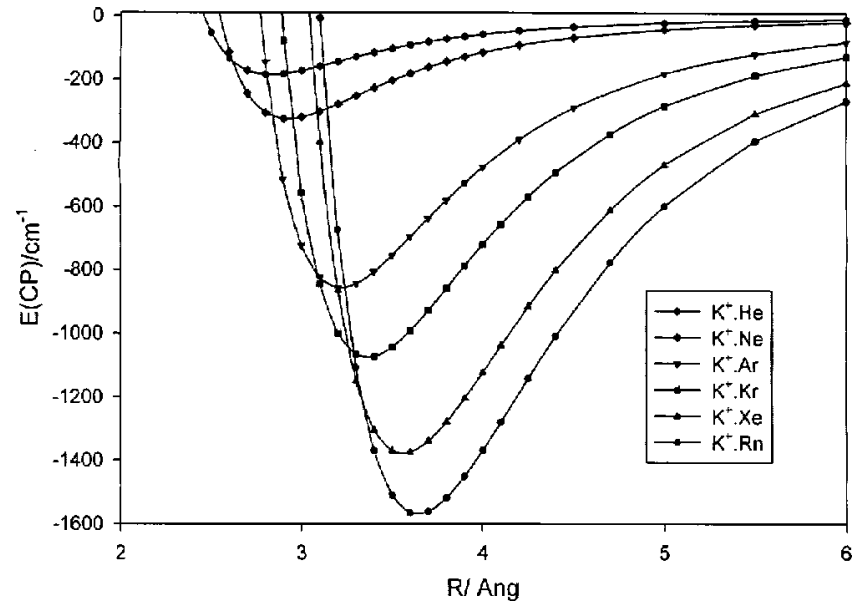

FIG. 1. Potential energy curves for the six $\mathrm{K}^{+} \cdot \mathrm{Rg}$ species calculated at the $\operatorname{CCSD}(\mathrm{T})$ level of theory. Basis sets used: d-aV5Z $\left(\mathrm{K}^{+} \cdot \mathrm{He}\right)$; aV5Z $\left(\mathrm{K}^{+}\right.$ $\cdot \mathrm{Ne}$ and $\mathrm{K}^{+} \cdot \mathrm{Ar}$ ), and ECP basis sets for $\mathrm{K}^{+} \cdot \mathrm{Kr}-\mathrm{K}^{+} \cdot \mathrm{Rn}$. See text for details.

that work, leading to a shallower potential and fewer bound levels. As noted above, comparison with mobility data in Refs. 28 and 29 has led to the conclusion that the mobilitymodified potential of Ref. 28 is very accurate, and so we compare to that potential also. Plots of that potential and our $\operatorname{CCSD}(\mathrm{T}) / \mathrm{d}$-aug-cc-pV5Z one lead to the conclusion that these are, indeed, very similar, with only very small differences observable by eye. The modified EFG potential given in Ref. 28 leads to values of $D_{e}=185.5 \mathrm{~cm}^{-1}$, and $R_{e}$ $=2.83 \AA$-both in very good agreement with the values obtained herein.

Vibrational energy levels and rotational constants are given in Table IV for the lowest few levels. Our best value for $\omega_{e}$ is $100.4 \mathrm{~cm}^{-1}$, which compares favorably with the value of $101.4 \mathrm{~cm}^{-1}$ obtained from the mobility-modified potential. The value of $94.4 \mathrm{~cm}^{-1}$ from the SAPT potential ${ }^{26}$ is not in such good agreement.

TABLE III. Energies of the bound rovibrational states $(v, J)$ of ${ }^{39} \mathrm{~K}^{+} \cdot{ }^{4} \mathrm{He}\left(\mathrm{cm}^{-1}\right)$. Relative to the dissociation limit $\left(D_{e}=185.393 \mathrm{~cm}^{-1}\right)$. Calculations performed at the $\operatorname{CCSD}(\mathrm{T}) / \mathrm{d}$-aug-cc-pV5Z level of theory.

\begin{tabular}{rrrrrrr}
\hline \hline & \multicolumn{7}{c}{$v$} \\
\cline { 2 - 7 }$J$ & \multicolumn{1}{c}{0} & 1 & 2 & 3 & 4 & 5 \\
\hline 0 & -136.930 & -66.873 & -27.203 & -8.630 & -1.781 & -0.136 \\
1 & -135.864 & -66.018 & -26.583 & -8.239 & -1.584 & -0.079 \\
2 & -133.733 & -64.313 & -25.349 & -7.466 & -1.206 & \\
3 & -130.542 & -61.765 & -23.515 & -6.333 & -0.682 & \\
4 & -126.297 & -58.385 & -21.100 & -4.874 & -0.081 & \\
5 & -121.008 & -54.190 & -18.133 & -3.142 & & \\
6 & -114.687 & -49.199 & -14.655 & -1.221 & & \\
7 & -107.346 & -43.441 & -10.719 & & & \\
8 & -99.004 & -36.948 & -6.401 & & & \\
9 & -89.680 & -29.763 & -1.813 & & & \\
10 & -79.400 & -21.941 & & & & \\
11 & -68.193 & -13.553 & & & & \\
12 & -56.092 & -4.699 & & & & \\
13 & -43.140 & & & & & \\
14 & -29.387 & & & & & \\
15 & -14.898 & & & & & \\
\hline \hline
\end{tabular}


TABLE IV. Calculated rovibrational spectroscopic constants for ${ }^{39} \mathrm{~K}^{+} \cdot \mathrm{Rg} .{ }^{\mathrm{a}}$

\begin{tabular}{|c|c|c|c|}
\hline$v$ & $E(v, 0)-E(0,0)$ & $B_{v} / \mathrm{cm}^{-1}$ & $D_{v} / \mathrm{cm}^{-1}$ \\
\hline \multicolumn{4}{|c|}{$\mathrm{K}^{+} \cdot{ }^{4} \mathrm{He}$} \\
\hline 0 & 0 & 0.533 & $8.953 \times 10^{-5}$ \\
\hline 1 & 70.06 & 0.427 & $15.29 \times 10^{-5}$ \\
\hline 2 & 109.73 & 0.310 & $25.94 \times 10^{-5}$ \\
\hline 3 & 128.30 & 0.197 & $40.87 \times 10^{-5}$ \\
\hline \multicolumn{4}{|c|}{$\mathrm{K}^{+} \cdot{ }^{20} \mathrm{Ne}$} \\
\hline 0 & 0 & 0.145 & $2.81 \times 10^{-6}$ \\
\hline 1 & 62.36 & 0.135 & $3.43 \times 10^{-6}$ \\
\hline 2 & 115.08 & 0.125 & $4.23 \times 10^{-6}$ \\
\hline 3 & 158.69 & 0.114 & $5.24 \times 10^{-6}$ \\
\hline \multicolumn{4}{|c|}{$\mathrm{K}^{+} .{ }^{40} \mathrm{Ar}$} \\
\hline 0 & 0 & $8.15 \times 10^{-2}$ & $3.49 \times 10^{-7}$ \\
\hline 1 & 77.35 & $7.93 \times 10^{-2}$ & $3.74 \times 10^{-7}$ \\
\hline 2 & 149.99 & $7.70 \times 10^{-2}$ & $4.04 \times 10^{-7}$ \\
\hline 3 & 217.97 & $7.46 \times 10^{-2}$ & $4.37 \times 10^{-7}$ \\
\hline \multicolumn{4}{|c|}{$\mathrm{K}^{+} \cdot{ }^{84} \mathrm{Kr}$} \\
\hline 0 & 0 & $5.54 \times 10^{-2}$ & $1.31 \times 10^{-7}$ \\
\hline 1 & 70.90 & $5.43 \times 10^{-2}$ & $1.38 \times 10^{-7}$ \\
\hline 2 & 138.78 & $5.32 \times 10^{-2}$ & $1.46 \times 10^{-7}$ \\
\hline 3 & 203.66 & $5.21 \times 10^{-2}$ & $1.54 \times 10^{-7}$ \\
\hline \multicolumn{4}{|c|}{$\mathrm{K}^{+} .{ }^{132} \mathrm{Xe}$} \\
\hline 0 & 0 & $4.40 \times 10^{-2}$ & $6.66 \times 10^{-8}$ \\
\hline 1 & 70.67 & $4.33 \times 10^{-2}$ & $6.90 \times 10^{-8}$ \\
\hline 2 & 139.09 & $4.26 \times 10^{-2}$ & $7.16 \times 10^{-8}$ \\
\hline 3 & 205.27 & $4.19 \times 10^{-2}$ & $7.44 \times 10^{-8}$ \\
\hline \multicolumn{4}{|c|}{$\mathrm{K}^{+} .222 \mathrm{Rn}$} \\
\hline 0 & 0 & $3.81 \times 10^{-2}$ & $4.55 \times 10^{-8}$ \\
\hline 1 & 69.16 & $3.76 \times 10^{-2}$ & $4.68 \times 10^{-8}$ \\
\hline 2 & 136.47 & $3.71 \times 10^{-2}$ & $4.83 \times 10^{-8}$ \\
\hline 3 & 201.93 & $3.66 \times 10^{-2}$ & $5.00 \times 10^{-8}$ \\
\hline
\end{tabular}

${ }^{\mathrm{a}} E(v, J)=E(v, 0)+B_{v} J(J+1)-D_{v} J^{2}(J+1)^{2}$.

We conclude that, on the basis of the spectroscopic constants, there is little difference between the mobilitymodified potential of Ref. 28, and the best potential obtained herein-we shall compare these potentials further when considering the calculated transport constants below.

\section{2. $\mathrm{K}^{+} \cdot \mathrm{Ne}$}

There has not been much work performed on $\mathrm{K}^{+} \cdot \mathrm{Ne}$. Ahlrichs et $_{\text {al. }}{ }^{23}$ derived a model potential for the system, and this was modified in the later work by Skullerud et al. ${ }^{29}$ where two adjustable parameters were used to fit the potential to mobility data - this is denoted the SLT potential hereafter. In addition, KMV (Ref. 25) also derived a model potential based upon a universal scaling procedure, again fitting to available mobility data. The two mobility-fitted potential energy curves ${ }^{25,29}$ give good agreement with each other, with Ref. 25 obtaining $R_{e}=2.97 \AA$ and $D_{e}=314 \mathrm{~cm}^{-1}$, and Ref. 29 obtaining corresponding values of $2.87 \AA$ and $350 \mathrm{~cm}^{-1}$. Again, in the present work, a wide range of $R$ was used to calculate the potential for this species using both the aVQZ and aV5Z basis sets, and LEVEL employed to obtain spectroscopic constants. The curve is shown in Fig. 1. As may be seen from Table II, reasonable agreement is obtained between the $\operatorname{CCSD}(\mathrm{T}) / \mathrm{aVQZ}$ and $\operatorname{CCSD}(\mathrm{T}) / \mathrm{aV} 5 \mathrm{Z}$ calculations, with the larger basis set giving $R_{e}=2.92 \AA$ and $D_{e}$
$=312 \mathrm{~cm}^{-1}$. These values are in good agreement with the potential energy curves obtained from fits to mobility data. $^{25,29}$

Vibrational energy levels and rotational constants are given in Table IV for the lowest few levels.

\section{3. $K^{+} \cdot A r$}

Ahlrichs et al. ${ }^{23}$ used a model potential to describe the $\mathrm{K}^{+} / \mathrm{Ar}$ system. This potential was modified by Skullerud and co-workers ${ }^{29}$ with parameters fitted to mobility data; they obtained a potential with $R_{e}=3.13 \AA$ and $D_{e}=938 \mathrm{~cm}^{-1}$. The earlier potential of $\mathrm{KMV}^{25}$ also obtained by fitting to available mobility data, had $R_{e}=3.11 \AA$ and $D_{e}$ $=990 \mathrm{~cm}^{-1}$. In addition, Bauschlicher et al. ${ }^{30}$ employed the modified coupled-pair functional (MCPF) approach, with large basis sets, to obtain $R_{e}=3.42 \AA$ and a dissociation energy of $490 \mathrm{~cm}^{-1}$, which seems to be very low.

It is worth noting in passing that scattering cross sections obtained from molecular beam studies have been used to derive information about the $\mathrm{K}^{+} \cdot \mathrm{Rg}$ systems. Powers and Cross $^{31}$ fitted their data to model potentials, obtaining a $D_{e}$ value of $758 \mathrm{~cm}^{-1}$ and an $R_{e}$ value of $3.49 \AA$, clearly out of line with the mobility studies. Perhaps this is not too surprising as such studies tend to be probing the repulsive region of the potential and, as noted in Ref. 6 , these studies were unable to gain any information on the lighter species, $\mathrm{K}^{+} \cdot \mathrm{He}$ and $\mathrm{K}^{+} \cdot \mathrm{Ne}$, presumably since the potential was too shallow.

The results from the present work are given in Table II, with the potential curve being presented in Fig. 1. As may be seen, the difference between the results using the $\operatorname{CCSD}(\mathrm{T}) /$ aVQZ and the CCSD(T)/aV5Z levels of theory is relatively small. Our best values are $D_{e}=856.8 \mathrm{~cm}^{-1}$ and $R_{e}$ $=3.215 \AA$. The dissociation energy is similar to that obtained in the mobility studies, ${ }^{25,29}$ but is far removed from the MCPF value ${ }^{30}$ (see Table II). The value for $\omega_{e}$ reported in Ref. 30 of $66 \mathrm{~cm}^{-1}$ is also rather low compared to our best value of $82 \mathrm{~cm}^{-1}$.

Vibrational energy levels and rotational constants are given in Table IV for the lowest few levels.

\section{4. $K^{+} \cdot K r$}

For this species, there are only two sources of potentials to the authors' knowledge. The first is Ref. 25 where potentials are reported, which (as noted above) were obtained by fitting to available mobility data. The second, more recent, one is that of Skullerud and co-workers, ${ }^{29}$ who again used a model potential with parameters fitted to further mobility data. For $\mathrm{K}^{+} \cdot \mathrm{Kr}$, the KMV potential yielded $R_{e}=3.30 \AA$ and $D_{e}=1135 \mathrm{~cm}^{-1}$, while the Skullerud potential gave corresponding values of $3.28 \AA$ and $1157 \mathrm{~cm}^{-1}$. These values compare favourably to those obtained herein: $D_{e}$ $=1075 \mathrm{~cm}^{-1}$ and $R_{e}=3.36 \AA$. In addition, we note that Powers and Cross ${ }^{31}$ obtained values of $D_{e}=686 \mathrm{~cm}^{-1}$ and $R_{e}=3.59 \AA$ from beam studies, and again these values seem to indicate a potential that is too shallow. 


\section{5. $K^{+} \cdot X e$}

For $\mathrm{K}^{+} \cdot \mathrm{Xe}$, the KMV potential ${ }^{25}$ yielded $R_{e}=3.35 \AA$ and $D_{e}=1721 \mathrm{~cm}^{-1}$, while the corresponding values from the Skullerud et al. potential ${ }^{29}$ were $3.46 \AA$ and $1510 \mathrm{~cm}^{-1}$. These values are in reasonable agreement with the values of $D_{e}=1378 \mathrm{~cm}^{-1}$ and $R_{e}=3.56 \AA$ obtained herein, but both appear to be a little deeper and more strongly bound than the present potentials, which are shown in Fig. 1. Again, the molecular beam studies yield a potential which seem to be too shallow, with $D_{e}=1210 \mathrm{~cm}^{-1}$ and $R_{e}=4.00 \AA$.

We also note the study of Freitag et al. ${ }^{32}$ who used the coupled-electron-pair approximation (CEPA) method to calculate properties of $\mathrm{M}^{+} \cdot \mathrm{Xe}$ species. They obtained values of: $R_{e}=3.77 \AA, D_{e}=900 \mathrm{~cm}^{-1}, \omega_{e}=57 \mathrm{~cm}^{-1}$, and $\omega_{e} x_{e}$ $=1.0 \mathrm{~cm}^{-1}$. As may be seen, by comparison both with the previous mobility potentials and the values obtained herein (Table II), Freitag et al.'s potential is also too shallow.

Vibrational energy levels and rotational constants are given in Table IV for the lowest few levels.

\section{6. $K^{+} \cdot R n$}

There have been no previous studies on the $\mathrm{K}^{+} \cdot \mathrm{Rn}$ systems, and so the spectroscopic values presented in Tables II and IV constitute the only ones available; the potential energy curve is given in Fig. 1. Our values are: $D_{e}$ $=1570 \mathrm{~cm}^{-1}, R_{e}=3.64 \AA$, and $\omega_{e}=71 \mathrm{~cm}^{-1}$.

\section{Rovibrational data for the $K^{+} \cdot R g$ species}

In Table IV are given the energies of the lowest few pure vibrational levels, and it is from these levels that the $\omega_{e}$ and $\omega_{e} x_{e}$ values in Table II are derived. One can see from Table II that the vibrational energies do not follow a monotonic trend with increasing molar mass: this may be understood by noting that there are two counteracting factors that are affecting the frequencies. First, as the mass of Rg increases, then the vibrational frequency would be expected to fall, all things being equal; but secondly, as Rg increases in size it becomes more polarizable, and so the interaction energy is expected to increase (as observed), which is expected to increase the frequency. These two effects are in competition and lead to the observed oscillation in the frequency. It is also seen that the anharmonicity of the vibration decreases as $\mathrm{Rg}$ increases in size: this is to be expected as the well-depth increases.

\section{B. Transport properties}

There have been many studies of the transport of $\mathrm{K}^{+}$in rare gases, with all gases having been studied except radon. For helium and argon in particular, the number of studies is quite large, covering a variety of transport coefficients over wide ranges of $E / N$, and at a variety of temperatures. For this reason, and as was the case for $\mathrm{Li}^{+}$and $\mathrm{Na}^{+}$(Refs. 5 and 6) we have placed the results in the gaseous ion transport database at Chatham College. ${ }^{33}$

The differences between the measured and calculated transport coefficients are compared using statistical quantities, $\delta$ and $\chi$, which take into account the estimated errors in each quantity. ${ }^{22}$ In order to compare the data informatively,

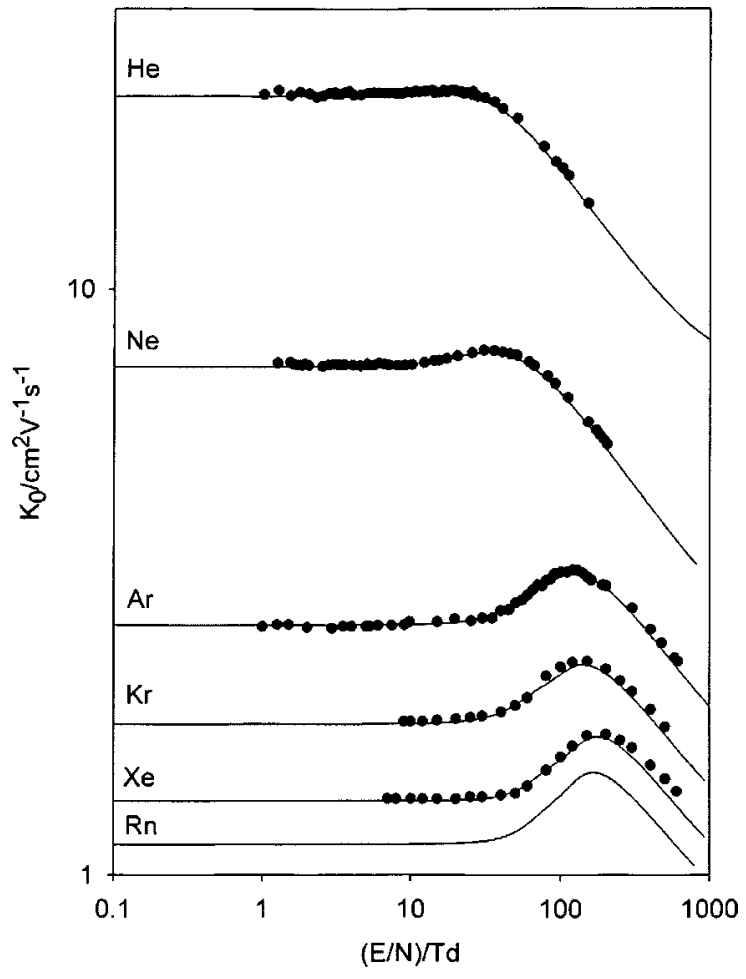

FIG. 2. Log-log plots of experimental and calculated mobility data for $\mathrm{K}^{+}$ in a bath of $\mathrm{Rg}$. The lines are the calculated data of the present work and the dots are the experimental data. The latter were taken from Ref. $38\left(\mathrm{~K}^{+}\right.$ $\left.\cdot \mathrm{He}, \mathrm{K}^{+} \cdot \mathrm{Ne}\right)$; Ref. $44\left(\mathrm{~K}^{+} \cdot \mathrm{Ar}\right)$; Ref. $52\left(\mathrm{~K}^{+} \cdot \mathrm{Kr}\right)$; Ref. $53\left(\mathrm{~K}^{+} \cdot \mathrm{Xe}\right)$.

some idea of the meanings of $\delta$ and $\chi$ is required. If the experimental and calculated errors are the same at all $E / N$, then $\delta$ is the ratio of the average percentage difference to the maximum combined percentage difference expected, while $\chi$ is the ratio of the standard deviation of the percentage differences to the root mean square of the maximum combined percentage deviations expected. A positive value of $\delta$ indicates that the data lie above the calculated values, and vice versa. Values of $|\delta|$ that are substantially lower (alternatively, higher) than 1 indicate that there is substantial agreement (disagreement) between the calculated and measured values, on average. Values of $\chi$ that are not much larger than $|\delta|$ indicate that there is little scatter in the experimental data and that the agreement between the calculated and measured values is uniform over all values of $E / N$, while values of $\chi$ substantially greater than $|\delta|$ indicate that at least one of these factors is not true. The statistical comparisons are performed at low, intermediate and high $E / N$ regions.

In Tables V-IX we present a statistical comparison of the calculated data with the experimental ones. See EPAPS Document No. E-JCPSA6-120-310421 for fuller versions of these tables that consider a much broader range of data. In the following we simply refer to a particular table, but the full information may only be available in the EPAPS extended version. ${ }^{34}$ To give the reader some idea of the performance of these potentials, we also present comparison of the calculated $K_{0}$ values in Fig. 2, together with a selected set of experimental data, for each of the species (except $\mathrm{K}^{+} \cdot \mathrm{Rn}$, for which no experiments have yet been reported). We summarize our conclusions in the following subsections. 
TABLE V. Statistical comparison of calculated and experimental transport data for $\mathrm{K}^{+}$ions in He gas. ${ }^{\mathrm{a}}$

\begin{tabular}{|c|c|c|c|c|c|c|c|c|c|c|c|c|c|c|c|c|c|c|}
\hline \multirow[b]{4}{*}{ Data type } & \multirow[b]{4}{*}{ Range of $E / N$} & \multirow[b]{4}{*}{$A$} & \multirow[b]{4}{*}{ No. } & \multicolumn{15}{|c|}{ Potential source } \\
\hline & & & & & & & & & & & & & & This wor & & & & \\
\hline & & & & \multicolumn{3}{|c|}{ Ref. 25} & \multicolumn{3}{|c|}{ Ref. 29} & \multicolumn{3}{|c|}{ aVQZ } & \multicolumn{3}{|c|}{ aV5Z } & \multicolumn{3}{|c|}{ d-aV5Z } \\
\hline & & & & $P$ & $\delta$ & $\chi$ & $P$ & $\delta$ & $\chi$ & $P$ & $\delta$ & $\chi$ & $P$ & $\delta$ & $\chi$ & $P$ & $\delta$ & $\chi$ \\
\hline$K_{0}$ & $9-20$ & 2 & 14 & 0.1 & -1.150 & 1.160 & 0.4 & -0.729 & 0.751 & 0.1 & -0.236 & 0.279 & 0.1 & 0.001 & 0.146 & 0.1 & 0.128 & 0.195 \\
\hline $303 \mathrm{~K}$ & $20-82$ & 2 & 18 & 0.1 & -0.765 & 0.801 & 0.4 & 0.143 & 0.412 & 0.1 & 0.080 & 0.242 & 0.1 & 0.093 & 0.200 & 0.1 & 0.143 & 0.217 \\
\hline Ref. 37 & $9-82$ & & 32 & & -0.93 & 0.98 & & -0.24 & 0.59 & & -0.06 & 0.26 & & 0.05 & 0.18 & & 0.14 & 0.21 \\
\hline $\begin{array}{l}K_{0} \\
76.8 \mathrm{~K} \\
\text { Ref. } 28\end{array}$ & $2-15$ & 0.5 & 11 & 0.1 & -3.342 & 3.573 & 0.4 & -3.198 & 3.335 & 0.1 & -0.773 & 1.075 & 0.1 & 0.373 & 0.630 & 0.1 & 0.590 & 0.682 \\
\hline$K_{0}$ & $2-19$ & 0.5 & 9 & 0.1 & -5.114 & 5.118 & 0.4 & -3.178 & 3.183 & 0.1 & -1.837 & 1.850 & 0.1 & -0.780 & 0.828 & 0.1 & -0.275 & 0.405 \\
\hline $294 \mathrm{~K}$ & $19-35$ & 0.5 & 4 & 0.1 & -4.155 & 4.182 & 0.4 & -1.329 & 1.453 & 0.1 & -1.240 & 1.291 & 0.1 & -0.837 & 0.858 & 0.1 & -0.539 & 0.559 \\
\hline Ref. 28 & $2-35$ & & 13 & & -4.82 & 4.85 & & -2.61 & 2.77 & & -1.65 & 1.70 & & -0.80 & 0.84 & & -0.36 & 0.46 \\
\hline$K_{0}$ & $2-29$ & 0.5 & 10 & 0.1 & -4.998 & 5.020 & 0.4 & -2.889 & 2.977 & 0.1 & -1.773 & 1.811 & 0.1 & -0.827 & 0.847 & 0.1 & -0.353 & 0.379 \\
\hline $295 \mathrm{~K}$ & $29-51$ & 0.5 & 4 & 0.1 & -3.012 & 3.024 & 0.4 & -0.031 & 0.478 & 0.1 & -0.208 & 0.324 & 0.1 & -0.118 & 0.159 & 0.1 & 0.074 & 0.097 \\
\hline \multirow[t]{2}{*}{ Ref. 28} & $51-300$ & 0.5 & 13 & 0.1 & -3.822 & 3.963 & 0.4 & 2.070 & 2.148 & 0.1 & 1.389 & 1.477 & 0.1 & 0.948 & 1.034 & 0.1 & 0.953 & 1.031 \\
\hline & $2-300$ & & 27 & & -4.14 & 4.27 & & -0.08 & 2.35 & & -0.02 & 1.51 & & 0.13 & 0.89 & & 0.34 & 0.75 \\
\hline$D_{\perp} / K 294 \mathrm{~K}$ & $4-19$ & 3 & 6 & 0.3 & -0.058 & 0.317 & 1 & 0.087 & 0.269 & 1 & 0.111 & 0.292 & 1 & 0.063 & 0.286 & 1 & 0.080 & 0.295 \\
\hline \multirow[t]{3}{*}{ Ref. 28} & $19-75$ & 3 & 8 & 0.3 & -0.797 & 0.902 & 1 & 0.557 & 0.705 & 1 & -0.054 & 0.371 & 1 & -0.265 & 0.429 & 1 & -0.299 & 0.444 \\
\hline & $75-220$ & 3 & 8 & 0.3 & -2.310 & 2.447 & 1 & 0.823 & 1.009 & 1 & 0.424 & 0.504 & 1 & 0.221 & 0.347 & 1 & 0.196 & 0.327 \\
\hline & $4-220$ & & 22 & & -1.15 & 1.58 & & 0.53 & 0.76 & & 0.16 & 0.41 & & 0.00 & 0.36 & & -0.02 & 0.37 \\
\hline
\end{tabular}

${ }^{\mathrm{a}} A=$ accuracy of experiment $(\%) . P=$ precision of calculations $(\%)$.

\section{1. $\mathrm{K}^{+}$in $\mathrm{He}$}

The experimental data has been reported in Refs. 28, 35-42, and our calculations are compared to those studies in Table V. The experimental studies cover a very wide range of temperature and $E / N$, providing a good set of data to which to compare the potential energy curves.

For all of the potentials, the $D_{\perp} / K$ data from Ref. 41 give $\delta$ values greater than 1 at low $E / N$, between -1 and +1 at intermediate $E / N$, and below -1 at high $E / N$. We conclude that these experimental data are significantly too high at low $E / N$, about right between 30 and $150 \mathrm{Td}$, and significantly too low at high $E / N$. In part, this conclusion comes from the high accuracy (2\%) claimed for these data, but primarily it points to a systematic error of unknown origin in the experiments.

With the possible exception of the KMV potential, ${ }^{25}$ none of the potentials match the diffusion data from Ref. 39 above $20 \mathrm{Td}$. This is consistent with recent experimental results for other atomic ion-atom systems ${ }^{43}$ that indicate that the Georgia Tech data at high $E / N$ suffer from a flawed method for extracting transport coefficients from the raw arrival time data. The flaw in the data analysis has a more serious impact on diffusion than on mobility, and so it is logical that disagreement begins at smaller $E / N$ for the $D_{\|}$ data.

The $80 \mathrm{~K}$ data from Ref. 42 shows considerable scatter, as evinced by large values of $\chi$, and they are poorly described by every potential studied, as indicated by $\delta$ values substantially below -1 , probably indicating that these values are not too reliable.

It was stated in 1991 (Ref. 41) that "none of the available potentials is completely correct." The only potential included here that was subject to this statement is the KMV one. ${ }^{25}$ Indeed, this potential describes well the mobility data from Ref. 38 that were used to determine its parameters, but it does not match the data obtained since 1991. The most logical reason for its poor agreement with the later data is that the mobility data in Ref. 38 is not as accurate as those for other systems; this is consistent with the fact that the $\delta$ values obtained for this system using other potentials are close to or slightly above the value of +1 that indicates a significant disagreement. We conclude that the KMV potential and the data from Ref. 38 are not reliable.

The potential curves from Refs. 26 and 27 are $a b$ initio potentials that match the experimental data from Refs. 3537,40 , and 41 moderately well. However, the $\delta$ values are consistently negative for the potential from Ref. 26, while those for the potential from Ref. 27 are approximately evenly split between positive and negative values. This suggests that the latter potential is a more accurate representation of the true $\mathrm{K}^{+} \cdot \mathrm{He}$ interaction potential than the former.

Only the potential from Ref. 28 and the current aV5Z and $\mathrm{d}-\mathrm{aV} 5 \mathrm{Z}$ potentials match the rest of the data with $|\delta|$ values $<1$ and with $\chi$ values smaller than 1 . This is particularly striking for the mobility data from Ref. 28, which are not only the most recent data but also have the highest claimed accuracy. Given that the aVQZ potential is not sufficient to describe the mobility data, it suggests that the demands on basis set for these rather simple systems is quite stringent. It appears a quintuple- $\zeta$ basis set is requiredlikely due to the weak nature of this interaction, caused by the low polarizability of the He atom.

In summary, the potential from Ref. 28 and the present $\operatorname{CCSD}(\mathrm{T}) / \mathrm{aV} 5 \mathrm{Z}$ and $\operatorname{CCSD}(\mathrm{T}) / \mathrm{d}-\mathrm{aV} 5 \mathrm{Z}$ potentials are the best available for this system. Only the present potentials are $a b$ initio potentials. Although most of the experimental data does not distinguish between these two potentials, the recent data from Ref. 28 is matched marginally better by the 
TABLE VI. Statistical comparison of calculated and experimental transport data for $\mathrm{K}^{+}$ions in $\mathrm{Ne}$ gas. ${ }^{\text {a }}$

\begin{tabular}{|c|c|c|c|c|c|c|c|c|c|c|c|c|c|c|c|}
\hline \multirow[b]{4}{*}{ Data type } & \multirow{4}{*}{$\begin{array}{c}\text { Range of } \\
E / N\end{array}$} & \multirow[b]{4}{*}{$A$} & \multirow{4}{*}{$\begin{array}{l}\text { No. of } \\
\text { points }\end{array}$} & \multicolumn{12}{|c|}{ Potential source } \\
\hline & & & & & & & & & & & & This & vork & & \\
\hline & & & & \multicolumn{3}{|c|}{ Ref. 25} & \multicolumn{3}{|c|}{ Ref. 29} & \multicolumn{3}{|c|}{ aVQZ } & \multicolumn{3}{|c|}{ aV5Z } \\
\hline & & & & $P$ & $\delta$ & $\chi$ & $P$ & $\delta$ & $\chi$ & $P$ & $\delta$ & $\chi$ & $P$ & $\delta$ & $\chi$ \\
\hline$K_{0}$ & $9-25$ & 2 & 10 & 0.1 & -0.017 & 0.089 & 1 & 0.423 & 0.428 & 0.1 & -0.304 & 0.315 & 0.1 & 0.045 & 0.097 \\
\hline $302 \mathrm{~K}$ & $25-81$ & 2 & 16 & 0.1 & 0.057 & 0.152 & 1 & 0.231 & 0.290 & 0.1 & 0.158 & 0.220 & 0.1 & 0.243 & 0.266 \\
\hline Ref. 37 & $9-81$ & & 26 & & 0.03 & 0.13 & & 0.30 & 0.35 & & -0.02 & 0.26 & & 0.16 & 0.22 \\
\hline$D_{\perp} / K$ & $4-25$ & 1 & 8 & 1 & -0.427 & 0.504 & 1 & -0.089 & 0.240 & 1 & -0.468 & 0.546 & 1 & -0.384 & 0.448 \\
\hline $295 \mathrm{~K}$ & $25-70$ & 1 & 7 & 1 & -1.013 & 1.023 & 1 & -0.347 & 0.417 & 1 & -0.625 & 0.667 & 1 & -0.560 & 0.587 \\
\hline \multirow[t]{2}{*}{ Ref. 29} & $70-350$ & 1 & 9 & 1 & -2.778 & 2.954 & 1 & -0.719 & 0.740 & 1 & -0.573 & 0.612 & 1 & -0.743 & 0.772 \\
\hline & $4-350$ & & 24 & & -1.42 & 1.86 & & -0.40 & 0.52 & & -0.55 & 0.61 & & -0.57 & 0.63 \\
\hline
\end{tabular}

${ }^{\mathrm{a}} A=$ accuracy of experiment (\%). $P=$ precision of calculations (\%).

CCSD(T)/d-aV5Z potential. Hence, this ab initio potential appears to be the best potential available for this system, but the differences between it, the $\operatorname{CCSD}(\mathrm{T}) / \mathrm{aV} 5 \mathrm{Z}$ one, and that of Ref. 28 are very small.

\section{2. $\mathrm{K}^{+}$in $\mathrm{Ne}$}

The experimental work on $\mathrm{K}^{+}$in $\mathrm{Ne}$ has been published in Refs. 29, 35-39. Again, the experimental studies cover a very wide range of temperatures and $E / N$, providing a good set of data to which to compare the potential energy curves. The comparison between the calculated transport data and the experimental is presented in Table VI.

All of the potentials match the available data except for the diffusion data ${ }^{39}$ at high $E / N$ from the Georgia Tech group. Again, this is consistent with a flawed method for extracting transport coefficients (see discussion above for $\mathrm{K}^{+} \cdot \mathrm{He}$ ). The present $a b$ initio potentials are at least as good, and are perhaps slightly better, at matching the data than are the two model potentials from Refs. 25 and 29, although this is not conclusive. The SLT model potential ${ }^{29}$ does the best job of fitting the data reported in the same paper, but that is natural since the potential parameters were fitted to that data. The fit of the present potentials to these recent data is acceptable. It is not conclusive whether the aVQZ or the aV5Z potentials of the present work perform better at describing the transport data or not; with each potential fitting some data better than the other. This inconclusiveness is due to the closeness of the two potentials.

\section{3. $\mathrm{K}^{+}$in $\mathrm{Ar}$}

The experimental work on $\mathrm{K}^{+}$in Ar has been published in Refs. 35-37, 41, 44-48. Again, a fairly wide range of $E / N$ and temperatures has been covered. Comparison of the calculated data with the experimental is given in Table VII, from which we make the following comments.

In 1991, Hogan and $\mathrm{Ong}^{49}$ concluded that the KMV potential $^{25}$ was the best one available at that time, in the sense that it did the best job of matching the experimental transport data. However, this potential is in significant or nearly significant disagreement with all of the data except that from Ref. 36, which was the data used to determine the parameter values for that model potential. We conclude that the mobility data from Ref. 36 is inaccurate and that the KMV potential for this system should no longer be considered reliable. The SLT model potential ${ }^{29}$ and the aVQZ and aV5Z potentials from the present work do not agree well with the experimental mobilities from Ref. 35, whether at

TABLE VII. Statistical comparison of calculated and experimental transport data for $\mathrm{K}^{+}$ions in $\mathrm{Ar}$ gas. ${ }^{\mathrm{a}}$

\begin{tabular}{|c|c|c|c|c|c|c|c|c|c|c|c|c|c|c|c|}
\hline \multirow[b]{4}{*}{ Data type } & \multirow[b]{4}{*}{ Range of $E / N$} & \multirow[b]{4}{*}{$A$} & \multirow[b]{4}{*}{ No. of points } & \multicolumn{12}{|c|}{ Potential source } \\
\hline & & & & & & & & & & \multicolumn{6}{|c|}{ This work } \\
\hline & & & & \multicolumn{3}{|c|}{ Ref. 25} & \multicolumn{3}{|c|}{ Ref. 29} & \multicolumn{3}{|c|}{$\mathrm{aVQZ}$} & \multicolumn{3}{|c|}{$\mathrm{aV} 5 \mathrm{Z}$} \\
\hline & & & & $P$ & $\delta$ & $\chi$ & $P$ & $\delta$ & $\chi$ & $P$ & $\delta$ & $\chi$ & $P$ & $\delta$ & $\chi$ \\
\hline$K_{0} 304 \mathrm{~K}$ & $9-46$ & 2 & 17 & 0.1 & 0.995 & 1.011 & 0.1 & 0.567 & 0.580 & 0.1 & -0.341 & 0.359 & 0.1 & 0.160 & 0.180 \\
\hline \multirow[t]{2}{*}{ Ref. 37} & $46-110$ & 2 & 15 & 0.3 & 1.220 & 1.259 & 0.3 & 1.959 & 2.034 & 0.3 & 0.177 & 0.446 & 0.3 & 0.679 & 0.779 \\
\hline & $9-110$ & & 32 & & 1.10 & 1.13 & & 1.22 & 1.46 & & -0.10 & 0.40 & & 0.40 & 0.55 \\
\hline$K_{0} 295 \mathrm{~K}$ & $3-46$ & 0.5 & 14 & 0.1 & 1.683 & 1.726 & 0.1 & 0.479 & 0.505 & 0.1 & -2.178 & 2.272 & 0.1 & -0.596 & 0.695 \\
\hline \multirow[t]{2}{*}{ Ref. 42} & $46-120$ & 0.5 & 8 & 0.3 & 3.530 & 3.667 & 0.3 & 3.806 & 4.052 & 0.3 & -0.539 & 1.240 & 0.3 & 2.006 & 2.390 \\
\hline & $3-120$ & & 22 & & 2.35 & 2.60 & & 1.69 & 2.48 & & -1.58 & 1.96 & & 0.45 & 1.61 \\
\hline$D_{\perp} / K 298 \mathrm{~K}$ & $10-46$ & 3 & 8 & 1 & 0.425 & 0.624 & 2 & 0.184 & 0.359 & 1 & -0.061 & 0.404 & 1 & 0.068 & 0.363 \\
\hline \multirow[t]{3}{*}{ Ref. 48} & $46-185$ & 3 & 10 & 3 & -0.698 & 0.879 & 5 & -0.283 & 0.401 & 3 & -0.595 & 0.664 & 3 & -0.415 & 0.499 \\
\hline & $185-600$ & 3 & 16 & 1 & -2.599 & 2.614 & 1 & -0.555 & 0.602 & 1 & -0.770 & 0.805 & 1 & -0.770 & 0.834 \\
\hline & $10-600$ & & 32 & & -1.41 & 1.94 & & -0.32 & 0.51 & & -0.59 & 0.71 & & -0.469 & 0.657 \\
\hline
\end{tabular}

${ }^{a} A=$ accuracy of experiment (\%). $P=$ precision of calculations (\%). 
TABLE VIII. Statistical comparison of calculated and experimental transport data for $\mathrm{K}^{+}$ions in $\mathrm{Kr}^{\text {gas. }}{ }^{\mathrm{a}}$

\begin{tabular}{|c|c|c|c|c|c|c|c|c|c|c|c|c|}
\hline \multirow[b]{3}{*}{ Data type } & \multirow[b]{3}{*}{ Range of $E / N$} & \multirow[b]{3}{*}{$A$} & \multirow[b]{3}{*}{ No. of points } & \multicolumn{9}{|c|}{ Potential source } \\
\hline & & & & \multicolumn{3}{|c|}{ Ref. 25} & \multicolumn{3}{|c|}{ Ref. 29} & \multicolumn{3}{|c|}{ This work } \\
\hline & & & & $P$ & $\delta$ & $\chi$ & $P$ & $\delta$ & $\chi$ & $P$ & $\delta$ & $\chi$ \\
\hline$D_{\perp} / K 295 \mathrm{~K}$ & $10-46$ & 1 & 8 & 1 & -0.131 & 0.286 & 1 & 0.055 & 0.186 & 1 & -0.053 & 0.272 \\
\hline \multirow[t]{3}{*}{ Ref. 29} & $46-185$ & 1 & 7 & 3 & -1.728 & 1.834 & 3 & -1.327 & 1.480 & 3 & -0.587 & 0.917 \\
\hline & $185-400$ & 1 & 5 & 1 & -3.083 & 3.109 & 1 & -1.559 & 1.598 & 1 & -1.010 & 1.075 \\
\hline & $10-400$ & & 20 & & -1.43 & 1.90 & & -0.83 & 1.19 & & -0.48 & 0.78 \\
\hline$D_{\perp} / K 298 \mathrm{~K}$ & $5-46$ & 2.5 & 9 & 1 & -0.059 & 0.438 & 1 & 0.066 & 0.483 & 1 & -0.015 & 0.425 \\
\hline \multirow[t]{3}{*}{ Ref. 41} & $46-185$ & 2.5 & 10 & 3 & -1.422 & 1.871 & 3 & -1.113 & 1.647 & 3 & -1.035 & 1.592 \\
\hline & $185-420$ & 2.5 & 10 & 1 & 1.045 & 1.086 & 1 & -0.201 & 0.358 & 1 & 0.117 & 0.371 \\
\hline & $5-420$ & & 29 & & -0.87 & 1.29 & & -0.43 & 1.03 & & -0.32 & 0.99 \\
\hline
\end{tabular}

${ }^{\mathrm{a}} A=$ accuracy of experiment $(\%) . P=$ precision of calculations $(\%)$.

$197 \mathrm{~K}$ or $275 \mathrm{~K}$. Given the remaining comments, we conclude that the experimental data are high by more than the $2 \%$ accuracy claimed for them.

The aVQZ potential matches the mobility data from Ref. 44 quite well, much better than the SLT model potential ${ }^{29}$ or indeed the aV5Z one. None of the potentials matches the parallel diffusion coefficient data at intermediate or high $E / N$, indicating that the diffusion data (unlike the mobility data) is not as accurate as claimed.

The aVQZ potential matches the mobility data from Ref. 45 quite well at low and intermediate $E / N$-much better than does the potential of Ref. 29 or the aV5Z one. The perpendicular diffusion data from Ref. 45 is adequately reproduced by all three potentials. Nevertheless, the calculated mobilities at high $E / N$ are not adequately represented by the potentials, suggesting that the experimental values at high $E / N$ are high by more than the $1.5 \%$ accuracy claimed for them.

The SLT model potential ${ }^{29}$ reproduces the mobility data from Ref. 36 with extraordinarily high precision at all $E / N$, whereas the current aVQZ and aV5Z potentials only reproduce them with moderate success. However, this situation is reversed for the mobility data from Ref. 37, making definitive conclusions difficult.

The mobility data from Ref. 46 is not well represented by the SLT model potential ${ }^{29}$ or the two current potentials, probably partly because the temperature varied substantially during the experiments, as noted therein.

The SLT model potential ${ }^{29}$ reproduces the mobility data from Ref. 47 with good precision at all $E / N$, much better than any other potential. The agreement is particularly striking at low $E / N$. However, the parallel diffusion data from the same work is not well described by any of the potentials, suggesting that it is too high by more than the 5\% accuracy claimed. It is also the case that the mobility data from Ref. 42 is not well represented by the SLT model potential ${ }^{29}$ or the two current potentials.

The SLT model potentials ${ }^{29}$ and the present aVQZ and aV5Z potentials represent the $D_{\perp} / K$ data from Ref. 48 quite well, which attests to their reliability since the accuracy claimed for these data is very good $(3 \%)$.

An overall assessment of these results, particularly the comparison with the results from Refs. 36 and 48, suggests that the SLT model potential ${ }^{29}$ and the present aVQZ potential are of approximately equal reliability and that the available experimental data do not clearly indicate which of the two potentials is likely to be closer to the true interaction potential for the $\mathrm{K}^{+}$. Ar system. Interestingly, the preponderance of the data suggest that the aV5Z potential is in slightly poorer agreement with the experimental data than is the aVQZ one-this is surprising since the larger basis set would be expected to be more reliable. Possible interpretations are that the aVQZ potential benefits from a cancellation of errors, or that the experimental data are not as accurate as claimed so that the statistics are leading to an incorrect conclusion. Only further experimental work will unravel this question.

\section{4. $\mathrm{K}^{+}$in $\mathrm{Kr}$}

The experimental data has been reported in Refs. 29, 41, 50, and 51. (Note that the data in Ref. 41 have been adjusted to $298 \mathrm{~K}$.) The statistics describing the comparison between the calculated data and the experimental is given in Table VIII. From these statistics it can be concluded that the KMV potential $^{25}$ only fits the mobility data from Ref. 51, i.e., the data from which the fitted parameters were derived. Given that this potential does not fit the diffusion data in Ref. 51, which was obtained by the same group, then the KMV potential $^{25}$ must be considered unreliable.

The SLT model potential ${ }^{29}$ and the present potential describe the complete set of experimental data with about the same reliability, although the SLT potential describes the mobility and diffusion data from the Georgia Tech group slightly better. Given the comments in the previous paragraph, it is likely that at least the diffusion data are actually of a lower accuracy than was claimed.

The present potential fits both sets of $D_{\perp} / K$ data better than does the SLT model potential. Overall, there is an indication that the present potential is slightly more accurate than is the SLT one; however it is not conclusive.

\section{5. $K^{+}$in $X e$}

The experimental data has been reported in Refs. 29, 50, and 51, and the statistics describing the comparison between the calculated data and the experimental is given in Table IX. 
TABLE IX. Statistical comparison of calculated and experimental transport data for $\mathrm{K}^{+}$ions in Xe gas. ${ }^{a}$

\begin{tabular}{|c|c|c|c|c|c|c|c|c|c|c|c|c|}
\hline \multirow[b]{3}{*}{ Data type } & \multirow[b]{3}{*}{ Range of $E / N$} & \multirow[b]{3}{*}{$A$} & \multirow[b]{3}{*}{ No. of points } & \multicolumn{9}{|c|}{ Potential source } \\
\hline & & & & \multicolumn{3}{|c|}{ Ref. 25} & \multicolumn{3}{|c|}{ Ref. 29} & \multicolumn{3}{|c|}{ This work } \\
\hline & & & & $P$ & $\delta$ & $\chi$ & $P$ & $\delta$ & $\chi$ & $P$ & $\delta$ & $\chi$ \\
\hline$D_{\perp} / K 295 \mathrm{~K}$ & $10-51$ & 1 & 9 & 1 & -0.120 & 0.157 & 1 & -0.142 & 0.207 & 1 & -0.414 & 0.572 \\
\hline \multirow[t]{3}{*}{ Ref. 29} & $51-151$ & 1 & 6 & 3 & -1.204 & 1.416 & 3 & -1.469 & 1.628 & 3 & -1.749 & 1.918 \\
\hline & $151-400$ & 1 & 5 & 1 & -3.480 & 3.505 & 1 & -1.110 & 1.131 & 1 & -0.571 & 0.613 \\
\hline & $10-400$ & & 20 & & -1.29 & 1.92 & & -0.78 & 1.06 & & -0.85 & 1.16 \\
\hline
\end{tabular}

${ }^{\mathrm{a}} A=$ accuracy of experiment (\%). $P=$ Precision of calculations (\%).

The KMV potential ${ }^{25}$ is found not to fit any of the experimental data very well; interestingly, not even the data from which the fitted parameters were obtained. ${ }^{50}$ The SLT model potential and the present $a b$ initio potential both fit the available data with about the same reliability, suggesting that both of these potentials are about as accurate as each other in describing the $\mathrm{K}^{+} \cdot \mathrm{Xe}$ interaction.

\section{6. $K^{+}$in $R n$}

Since there is no experimental data, nor any previous theoretical work, then no comparison for this system can be made. An example of the calculated data is, however, presented in Fig. 2.

\section{CONCLUSIONS}

Both the calculated spectroscopic data and transport data point to the present $a b$ initio potentials being extremely accurate. It is important to note that the potentials calculated here, the spectroscopic parameters and the transport data are all $a b$ initio and consequently have no adjustable parameters anywhere. The excellent agreement with the model potentials of Skullerud et al. ${ }^{29}$ which were based on a simple model potential with parameters fitted to accurate mobility data, and the present potentials indicate that truly reliable potentials are available for the $\mathrm{K}^{+} \cdot \mathrm{He}-\mathrm{K}^{+} \cdot \mathrm{Rn}$ species. Interestingly, there was not always a clear indication that the aV5Z basis set was performing better than the smaller aVQZ ones for $\mathrm{K}^{+} \cdot \mathrm{He}-\mathrm{K}^{+} \cdot \mathrm{Ar}$; indeed, sometimes the indications were that the performance was the opposite to expectations. The only reasonable conclusion to draw from this is that this is an artifact caused by the statistical analysis, which builds in the accuracy of the experimental data. Although it might be argued that better experiments might be able to spread some light on this matter, many of the experiments are already extremely accurate. We do note that we have used a combination of all-electron and ECP-based basis sets, and that consequently, there is some inconsistency in the treatment of core-correlation effects and the inclusion of relativistic effects; however, the large valence basis sets used in all cases ought to be able to describe the interactions here adequately.

We were also able, based on the large body of data available and a statistical analysis, to make conclusions as to the reliability of the different sets of diffusion and mobility data, and also to make similar comments regarding potentials.
In conclusion, in this work we have calculated very accurate $a b$ initio potentials for the set of six $\mathrm{K}^{+} \cdot \mathrm{Rg}$ species, and have shown that these are able to reproduce even very accurate transport data.

\section{ACKNOWLEDGMENTS}

The authors are grateful to the EPSRC for the award of computer time at the Rutherford Appleton Laboratories under the auspices of the Computational Chemistry Working Party (CCWP), which enabled these calculations to be performed, and for a studentship to J.L. E.P.F.L. is grateful to the Research Grant Council (RGC) of the Hong Kong Special Administration Region (HKSAR) and the Research Committee of the Hong Kong Polytechnic University for support. P.S. would like to thank the EPSRC for his present funding at Durham (Senior Research Assistantship). The work of L.A.V. was supported by the National Science Foundation.

${ }^{1}$ F. E. Budenholzer, J. J. Galante, E. A. Gislason, and A. D. Jorgensen, Chem. Phys. Lett. 33, 245 (1975).

${ }^{2}$ F. E. Budenholzer, E. A. Gislason, and A. D. Jorgensen, J. Chem. Phys. 78, 5279 (1983).

${ }^{3}$ L. A. Viehland and E. A. Mason, Ann. Phys. (N.Y.) 91, 499 (1975).

${ }^{4}$ I. R. Gartland, L. A. Viehland, and E. A. Mason, J. Chem. Phys. 66, 537 (1977).

${ }^{5}$ J. Lozeille, E. Winata, P. Soldán, E. P. F. Lee, L. A. Viehland, and T. G. Wright, Phys. Chem. Chem. Phys. 4, 3601 (2002).

${ }^{6}$ L. A. Viehland, J. Lozeille, P. Soldán, E. P. F. Lee, and T. G. Wright, J. Chem. Phys. 119, 3729 (2003).

${ }^{7}$ D. Bellert and W. H. Breckenridge, Chem. Rev. (Washington, D.C.) 102, 1595 (2002).

${ }^{8}$ P. Soldán, E. P. F. Lee, and T. G. Wright, Phys. Chem. Chem. Phys. 3, 4661 (2001).

${ }^{9}$ J. J. Wood and A. M. Boring, Phys. Rev. B 18, 27016 (1978).

${ }^{10}$ E. P. F. Lee and T. G. Wright, J. Phys. Chem. A 103, 7843 (1999).

${ }^{11}$ E. P. F. Lee, S. D. Gamblin, and T. G. Wright, Chem. Phys. Lett. 322, 377 (2000).

${ }^{12}$ E. P. F. Lee and T. G. Wright, Mol. Phys. 101, 405 (2003).

${ }^{13}$ EMSL Basis Set Library. Basis sets were obtained from the Extensible Computational Chemistry Environment Basis Set Database, Version $1 / 29 / 01$, as developed and distributed by the Molecular Science Computing Facility, Environmental and Molecular Sciences Laboratory which is part of the Pacific Northwest Laboratory, P.O. Box 999, Richland, Washington 99352, USA, and funded by the U.S. Department of Energy. The Pacific Northwest Laboratory is a multi-program laboratory operated by Battelle Memorial Institute for the U.S. Department of Energy under Contract No. DE-AC06-76RLO 1830. Contact David Feller or Karen Schuchardt for further information.

${ }^{14}$ E. P. F. Lee and T. G. Wright, Chem. Phys. Lett. 363, 139 (2002).

${ }^{15}$ T. Leininger, A. Nicklass, W. Küchle, H. Stoll, M. Dolg, and A. Bergner, Chem. Phys. Lett. 255, 274 (1996).

${ }^{16}$ S. F. Boys and F. Bernardi, Mol. Phys. 19, 533 (1970). 
${ }^{17}$ MOLPRO is a package of $a b$ initio programs written by H.-J. Werner, P. J. Knowles, with contributions from J. Almlöf, R. D. Amos, A. Berning et al. The CCSD treatment is described in C. Hampel, K. Peterson, and H. J. Werner, Chem. Phys. Lett. 190, 1 (1992).

${ }^{18}$ P. Soldán, E. P. F. Lee, and T. G. Wright, J. Chem. Soc., Faraday Trans. 94, 3307 (1998).

${ }^{19}$ R. J. Le Roy, LEVEL 7.2, A computer program for solving the radial Schrödinger equation for bound and quasibound levels, and calculating various expectation values and matrix elements (University of Waterloo Chemical Physics Research Program Report CP-555R, 2000).

${ }^{20}$ L. A. Viehland, Comput. Phys. Commun. 142, 7 (2001).

${ }^{21}$ L. A. Viehland, Chem. Phys. 70, 149 (1982).

${ }^{22}$ L. A. Viehland, Chem. Phys. 179, 71 (1994).

${ }^{23}$ R. Ahlrichs, H. J. Bohm, S. Brode, K. T. Tang, and J. P. Toennies, J. Chem. Phys. 88, 6290 (1988).

${ }^{24}$ G. R. Ahmadi, J. Almlöf, and I. Røeggen, Chem. Phys. 119, 33 (1995).

${ }^{25}$ A. D. Koutselos, E. A. Mason, and L. A. Viehland, J. Chem. Phys. 93, 7125 (1990).

${ }^{26}$ R. Moszynski, B. Jeziorski, G. H. F. Diercksen, and L. A. Viehland, J. Chem. Phys. 101, 4697 (1994).

${ }^{27}$ I. Røeggen, H. R. Skullerud, and M. T. Elford, J. Phys. B 29, 1913 (1996).

${ }^{28}$ H. R. Skullerud, M. T. Elford, and I. Røeggen, J. Phys. B 29, 1925 (1996).

${ }^{29}$ H. R. Skullerud, T. H. Lovaas, and K. Tsurugida, J. Phys. B 32, 4509 (1999).

${ }^{30}$ C. W. Bauschlicher, Jr., H. Partridge, and S. R. Langhoff, J. Chem. Phys. 91, 4733 (1989).

${ }^{31}$ T. R. Powers and R. J. Cross, Jr., J. Chem. Phys. 58, 626 (1973).

${ }^{32}$ A. Freitag, C. van Wüllen, and V. Staemmler, Chem. Phys. 192, 267 (1995).

${ }^{33}$ To access this database you must telnet to the computer named sassafrass.chatham.edu and $\log$ on as gastrans. The required password will be provided upon request by email to viehland@sassafrass.chatham.edu.

${ }^{34}$ See EPAPS Document No. E-JCPSA6-120-310421 for extended versions of Tables V-IX. A direct link to this document may be found in the online article's HTML reference section. The document may also be reached via the EPAPS homepage (http://www.aip.org/pubservs/epaps.html) or from ftp.aip.org in the directory /epaps/. See the EPAPS homepage for more information.

${ }^{35}$ R. P. Creaser, Ph.D. thesis, Australian National University, 1969 (unpublished).

${ }^{36}$ H. B. Milloy and R. E. Robson, J. Phys. B 6, 1139 (1973).

${ }^{37}$ R. P. Creaser, J. Phys. B 7, 529 (1974).

${ }^{38}$ D. R. James, E. Graham, G. R. Akridge, and E. W. McDaniel, J. Chem. Phys. 62, 740 (1975).

${ }^{39}$ D. R. James, E. Graham, G. R. Akridge, I. R. Gatland, and E. W. McDaniel, J. Chem. Phys. 62, 1702 (1975).

${ }^{40}$ N. Takata, J. Phys. B 8, 2390 (1975).

${ }^{41}$ M. J. Hogan and P. P. Ong, J. Chem. Phys. 95, 1973 (1991).

${ }^{42}$ R. A. Cassidy and M. T. Elford, 3rd International Swarm Seminar Proceedings, Innsbruck, 1983, Aust. J. Phys. 39, 25 (1986).

${ }^{43}$ T. H. Lovaas, H. R. Skullerud, O.-H. Kristensen, and D. Lihjell, J. Phys. D 20, 1465 (1990).

${ }^{44}$ Technical Report, Georgia Tech., 1972, subsequently published in D. R. James, E. Graham IV, G. M. Thomson, I. R. Gatland, and E. W. McDaniel, J. Chem. Phys. 58, 3652 (1973).

${ }^{45}$ H. R. Skullerud, Technical Report No. EIP 72-3, University of Trondheim, Norway, 1972.

${ }^{46}$ N. Takata, J. Phys. B 10, 2749 (1977). Data actually obtained at 295-311 $\mathrm{K}$.

${ }^{47}$ M. Takebe, Y. Satoh, K. Iinuma, and K. Seto, J. Chem. Phys. 73, 4071 (1980).

${ }^{48}$ P. P. Ong and M. J. Hogan, J. Phys. B 24, 633 (1991).

${ }^{49}$ M. J. Hogan and P. P. Ong, Phys. Rev. A 44, 1597 (1991).

${ }^{50}$ D. R. Lamm, M. G. Thackston, F. L. Eisele, H. W. Ellis, J. R. Twist, W. M. Pope, I. R. Gatland, and E. W. McDaniel, J. Chem. Phys. 74, 3042 (1981).

${ }^{51}$ W. M. Pope, F. L. Eisele, M. G. Thackston, and E. W. McDaniel, J. Chem. Phys. 69, 3874 (1978).

${ }^{52}$ Smoothed data taken from H. W. Ellis, E. W. McDaniel, D. L. Albritton, L. A. Viehland, S. L. Lin, and E. A. Mason, At. Data Nucl. Data Tables 22, 179 (1978).

${ }^{53}$ Smoothed data from H. W. Ellis, R. Y. Pai, E. W. McDaniel, E. A. Mason, and L. A. Viehland, At. Data Nucl. Data Tables 17, 177 (1976). 